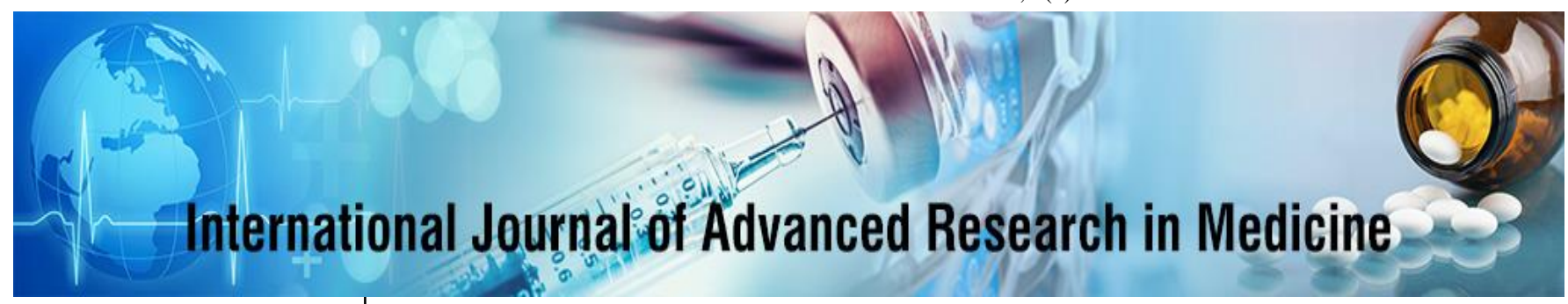

E-ISSN: 2706-9575

P-ISSN: 2706-9567

IJARM 2020; 2(2): 198-201

Received: 02-10-2020

Accepted: 20-11-2020

Dr. Nagendra S

Associate Professor,

Department of General

Medicine, Subbaiah Institute

of Medical Sciences,

Shivamogga, Karnataka, India

Dr. Riyas C

Assistant Professor,

Department of General

Medicine, Subbaiah Institute

of Medical Sciences,

Shivamogga, Karnataka, India

\section{Comparative study of acute ischemic stroke in Indian patients on dual anti-platelet therapy clopidogrel and aspirin versus aspirin using modified ranking scale}

\author{
Dr. Nagendra S and Dr. Dayananda AS
}

DOI: https://doi.org/10.22271/27069567.2020.v2.i2c.87

\begin{abstract}
Background: Stroke is a major cause of morbidity and mortality in an aging population. In the elderly, ischemic stroke accounts for more than $80 \%$ of all stroke cases. Stroke is the second leading cause of disability after ischaemic heart disease (IHD) and is the sixth leading cause worldwide. The aim of this study was to evaluate the effects of clopidogrel and aspirin (combination therapy) and aspirin alone (monotherapy for Acute Ischemic Stroke patients.

Material and Methods: This is a Prospective, non-randomized and observational study conducted in the Department of General Medicine, Subbaiah Institute of Medical Sciences, Shimoga among 70 acute ischemic stroke patients from January 2019 to September 2019. Clopidogrel at an initial dose of 300 $\mathrm{mg}$, followed by $75 \mathrm{mg}$ per day for 90 days, plus aspirin at a dose of $75 \mathrm{mg}$ per day for the first 21 days) or aspirin (75 $\mathrm{mg}$ per day for 90 days) group.

Result: In our study, majority of patients were more than 60 years and least were less than 40 years in both the groups. Predominant were male than female in both the groups. An mRS of 3-6 at 90-day assessment occurred in 3 patients in the clopidogrel-aspirin group, and in 3 patients in the aspirin group $(\mathrm{p}=0.039)$. Poor quality of life at 90 days occurred in 1 patients in the clopidogrel aspirin group and in 2 in the aspirin group $(\mathrm{p}=0.081)$.

Conclusions: For patients with acute Acute Ischemic Stroke, treatment with clopidogrel and aspirin provided significantly greater inhibition of platelet activity than aspirin alone. Thus, dual therapy can be safer and more effective in reducing ischemic stroke recurrence.
\end{abstract}

Keywords: acute ischemic stroke, dual anti-platelet therapy, clopidogrel, aspirin

\section{Introduction}

The WHO has defined stroke as "rapidly developed clinical signs of focal and at times global disturbances of cerebral function lasting more than 24 hours or leading to death, with no apparent cause other than vascular origin." It is one of the leading causes of adult disability and the second most common cause of death ${ }^{[1]}$. Stroke is a major cause of morbidity and mortality in an aging population. In the elderly, ischemic stroke accounts for more than $80 \%$ of all stroke cases ${ }^{[2]}$.

Stroke is the second leading cause of disability after ischaemic heart disease (IHD) and is the sixth leading cause worldwide. Women have a higher lifetime risk of stroke than men: about one in five women $(20 \%$ to $21 \%)$ and one in six men (14\% to $17 \%)$ will suffer a stroke in their lifetime, according to a study ${ }^{[3]}$. The prevalence of stroke events is expected to increase across the globe as the global population aged over 65 increases. The number of stroke events is projected to rise from 1.1 million in 2000 to 1.5 million per year by 2025 , largely due to the ageing population ${ }^{[4]}$. Clopidogrel is one of the most widely used antiplatelet agents worldwide. It has an established position as an antagonist of platelet function, leading to a reduced risk of recurrent ischemic events. Due to the updated guidelines on stroke, this drug is also increasingly being used for the secondary prevention of ischemic stroke. ${ }^{[5]}$ It might be used as a monotherapy as reasonable and equivalent option to aspirin in nonembolic ischemic stroke patients or in combination with aspirin for 21 days of dual antiplatelet therapy following a minor ischemic stroke or transient ischemic attack (TIA) in patients with a higher risk of recurrent stroke.

Aspirin is also known as Acetylsalicylic acid (ASA), irreversibly inactivates platelet cyclooxygenase, which is responsible for prostaglandin and thromboxane synthesis.
Corresponding Author:

Dr. Riyas C

Assistant Professor,

Department of General

Medicine, Subbaiah Institute

of Medical Sciences,

Shivamogga, Karnataka, India 
In particular, aspirin irreversibly blocks production of thromboxane A2. Thromboxane A2 is a potent platelet activator and pro-aggregant; hence by blocking thromboxane A2 synthesis, ASA is able to achieve an antiplatelet effect ${ }^{[6]}$. Aspirin and may then be continued longer term or switched to a different antiplatelet agent. Aspirin has the advantage of being less expensive than the other antiplatelet medications ${ }^{[7]}$.

Some relevant papers have demonstrated clopidogrel efficacy and safety and, in some cases, its advantage over aspirin ${ }^{[8]}$. However, the inhibition of platelets among different subjects might be limited and variable. This phenomenon is caused by multiple factors, leading to a reduced response of platelets, which may limit the therapeutic effect of the drug. Failure to achieve a drug response is referred to as clopidogrel resistance or high ontreatment platelet reactivity, and this has become the most important factor inhibiting the antiplatelet effect of the agent, resulting in ineffectiveness [9]. Therefore, various assays are used to assess platelet function for monitoring antiplatelet therapy ${ }^{[10]}$. They not only allow the phenomenon to be detected but can also estimate the level of platelet inhibition, thus allowing the effectiveness of the therapy to be assessed. It is extremely important for stroke subjects for whom responsiveness to antiplatetet agents is crucial.

\section{Material and Methods}

Study Design: This is a Prospective, non-randomized and observational study conducted in the Department of General Medicine, Subbaiah Institute of Medical Sciences, Shimoga among 70 acute ischemic stroke patients from January 2019 to September 2019. Clopidogrel at an initial dose of $300 \mathrm{mg}$, followed by $75 \mathrm{mg}$ per day for 90 days, plus aspirin at a dose of $75 \mathrm{mg}$ per day for the first 21 days) or aspirin (75 mg per day for 90 days) group.

Inclusion criteria: Patients who were at least 18 years of age were enrolled if they could undergo randomization within 12 hours after having an acute ischemic stroke with a score of 3 or less on the National Institutes of Health Stroke Scale (NIHSS) (scores range from 0 to 42, with higher scores indicating greater stroke severity). They were also required to undergo computed tomography or magnetic resonance imaging to rule out intracranial bleeding or other conditions that could explain the neurologic symptoms or detect any contraindications to a study treatment.

Exclusion Criteria: Patients who have received thrombolysis, endovascular therapy, or endarterectomy; had planned use of antiplatelet therapy or anticoagulation therapy (including those with presumed atrial fibrillation or cardiovascular disease, in whom anticoagulation would be indicated).

- Patients who have symptoms numbness, isolated visual changes, or isolated dizziness or vertigo or if they had received any thrombolytic therapy within 1 week before the event.

- Patients who have serious liver and kidney dysfunction or heart and lung diseases, malignant tumours, gastrointestinal disorders seriously affect drug absorption, coagulopathy or systemic bleeding illness or history and thrombocytopenia or neutropenia or history, pregnancy or breastfeeding women, recent surgery, trauma, or any plan for major surgery.

- Patients had a contraindication to aspirin or clopidogrel; or had anticipated use of a nonsteroidal antiinflammatory drug for more than 7 days during the trial period.

Modified Rankin Scale (mRS): Severity of functional outcome was measured by $\mathrm{mRS}$ (scores range from 0 [no symptoms] to 6 [death]) at 90 days. The primary outcome was dependence or death, defined as mRS of 2-6.

We also compared ordinal stroke severity of 2 treatment groups, that is, 3-level ordinal stroke scale with stroke ordered by its severity using mRS at 90 days: no stroke, nondisabling stroke (mRS $0-1$ ), or disabling stroke including fatal stroke ( $\mathrm{mRS} 2-6)$.

\section{Statistical analysis}

We performed the nonparametric test to see if there was a difference in the original $\mathrm{mRS}(0-6)$ as an ordinal variable between treatment and control groups. Meanwhile, we built the ordinal logistic regression model with the aspirin group as reference to test whether patients on clopidogrel and those on aspirin had the same mRS scores by grouping mRS into 3 levels (0-2, 3-4, and 5-6). With regard to quality of life, we made exploratory analysis for comparing differences in each of 5 EQ-5D domains (mobility, selfcare, usual activity, pain or discomfort, and anxiety or depression) by using the $\mathrm{x} 2$ test. We also made overall comparison on rate of 3-level ordinal stroke scale (no stroke, nondisabling stroke, and disabling stroke) between 2 treatment groups using the $\mathrm{x} 2$ test and further looked at these 2 contrasts with Bonferroni correction (no stroke vs nondisabling stroke, no stroke vs disabling stroke). The reason for stratified analysis by stroke was to determine whether better outcomes in functional status or quality of life were due to reduction in stroke as reported in main chance results. All analyses were conducted with SPSS version $20^{\text {th }}$ software. $p$ values less than 0.05 were considered to be statistically significant.

\section{Result}

In table 1 , majority of patients were more than 60 years and least were less than 40 years in both the groups. Predominant were male than female in both the groups.

Table 1: Distribution of Age group between two groups

\begin{tabular}{|c|c|c|}
\hline Age (Years) & Aspirin $(\mathrm{n}=35)$ & Clopidogrel and aspirin $(\mathrm{n}=35)$ \\
\hline$<40$ & 7 & 6 \\
\hline $41-60$ & 13 & 15 \\
\hline$>61$ & 15 & 14 \\
\hline Total & 35 & 35 \\
\hline
\end{tabular}

Table 2: Distribution of gender between two groups

\begin{tabular}{|c|c|c|}
\hline Gender & Aspirin $(\mathbf{n}=\mathbf{3 5})$ & Clopidogrel and aspirin $(\mathbf{n}=\mathbf{3 5})$ \\
\hline Male & 26 & 22 \\
\hline Female & 9 & 13 \\
\hline Total & 35 & 35 \\
\hline
\end{tabular}

In table 2 , in our study, predominant were male than female in both the groups. 
Table 3: Distribution of Modified Rankin Scale between two groups

\begin{tabular}{|c|c|c|}
\hline $\begin{array}{c}\text { mRS score before the onset of } \\
\text { index events }\end{array}$ & $\begin{array}{c}\text { Aspirin } \\
(\mathbf{n = 3 5})\end{array}$ & $\begin{array}{c}\text { Clopidogrel and } \\
\text { aspirin (n=35) }\end{array}$ \\
\hline 0 & 25 & 26 \\
\hline 1 & 9 & 7 \\
\hline 2 & 1 & 2 \\
\hline
\end{tabular}

Table 4: Functional outcome and quality of life at 90 days in patients after the index ischemic stroke

\begin{tabular}{|c|c|c|c|}
\hline Outcomes at 90 days & $\begin{array}{c}\text { Aspirin } \\
(\mathbf{n = 3 5})\end{array}$ & $\begin{array}{c}\text { Clopidogrel } \\
\text { and aspirin } \\
(\mathbf{n}=\mathbf{3 5})\end{array}$ & $\begin{array}{c}\mathbf{p} \\
\text { value }\end{array}$ \\
\hline $\mathrm{mRS}$ score: 2 to 6 vs 0 to 1 & & & 0.041 \\
\hline 0 to 1 & 28 & 29 & \\
\hline 2 to 6 & 7 & 6 & \\
\hline mRS score: 3 to 6 vs 0 to 2 & & & 0.039 \\
\hline 0 to 2 & 31 & 32 & \\
\hline 3 to 6 & 4 & 3 & \\
\hline Poor quality of life measured by EQ-5D & 2 & 1 & 0.081 \\
\hline
\end{tabular}

Poor functional outcome (mRS of 2-6) at 90 days occurred in 6 patients in the clopidogrel aspirin group, as compared with 7 patients in the aspirin group (absolute difference of poor outcome, $1.70 \%$; $95 \%$ CI $0.03 \%-3.42 \%$; $\mathrm{p}=0.041$ ); the number needed to treat to avoid a functional disability over 90 days is 59. An mRS of 3-6 at 90-day assessment occurred in 3 patients in the clopidogrel-aspirin group, and in 3 patients in the aspirin group $(\mathrm{p}=0.039)$. Poor quality of life at 90 days occurred in 1 patients in the clopidogrel aspirin group and in 2 in the aspirin group $(\mathrm{p}=0.081)$ (table $4)$.

Table 5: Distribution of 3-level ordinal stroke scale by treatment regimen in acute ischemic stroke

\begin{tabular}{|c|c|c|}
\hline $\begin{array}{c}\text { 3-level ordinal } \\
\text { stroke }\end{array}$ & $\begin{array}{c}\text { Aspirin } \\
(\mathbf{n = 3 5})\end{array}$ & $\begin{array}{c}\text { Clopidogrel and aspirin } \\
(\mathbf{n = 3 5})\end{array}$ \\
\hline No stroke & 25 & 26 \\
\hline Non disabling stroke & 9 & 7 \\
\hline Disabling Stroke & 1 & 2 \\
\hline
\end{tabular}

Table 6: Adjusted odds ratios for poor functional outcome and quality of life among patients with subsequent stroke or not

\begin{tabular}{|l|c|c|c|c|}
\hline $\begin{array}{c}\text { Outcomes } \\
\text { No stroke }\end{array}$ & Overall & $\begin{array}{c}\text { Number of poor } \\
\text { outcomes (\%) }\end{array}$ & Adjusted odds \\
\cline { 3 - 5 } & Aspirin & $\begin{array}{c}\text { Clopidogre } \\
\text { and aspirin }\end{array}$ & \\
ratio (95\% CI)
\end{tabular}

Adjusted ORs in 2 subgroups stratified by stroke are reported in table 6. Among patients with no stroke at 90 days, there were no differences between 2 study groups in 90-day mRS of 2-6 (adjusted OR 1.01; 95\% CI 0.63-1.21; $\mathrm{p}=0.63$ ), in 90-day mRS of 3-6 (adjusted OR 1.11; 95\% CI $0.53-2.11 ; \mathrm{p}=0.51$ ), or in poor quality of life (adjusted OR 1.03 ; 95\% CI $0.43-2.12 ; \mathrm{p}=0.73$ ), after the adjustment of baseline age remaining unbalanced in 2 study groups. Among patients with a stroke during follow-up, there were also no differences between 2 study groups in 90-day mRS of 2-6 (adjusted OR 1.13; 95\% CI 0.73-1.83; p=0.36), in 90-day mRS of 3-6 (adjusted OR 1.12 ; 95\% CI $0.63-1.32$; $\mathrm{p}=0.48$ ), or in poor quality of life (adjusted OR $1.02 ; 95 \%$ CI $0.63-1.62 ; \mathrm{p}=0.46)$.

\section{Discussion}

The events resulting from any subtype of ischemic stroke result in the loss of blood supply, oxygen, nutrients and elimination of metabolic wastes. These resulting changes obstruct normal neuronal functioning [11]. This ultimately results in neuronal death/necrosis from occlusion of the vessel. The brain tissue is exquisitely sensitive to these changes, and the therapeutic window that is needed to prevent reversible ischemia from becoming irreversible infarction is narrow and stresses the phrase "time is brain" [12]. This concept is especially important to minimizing evolving insult and controlling the propagation of ischemic penumbra ${ }^{[13]}$. Furthermore, from a therapeutic point of view, this crucial time provides a "window of opportunity" in reversing the neurological symptoms either partly or completely through acute interventional approaches, either invasively or non-invasive ${ }^{[14]}$.

In our study, we found that the combination of clopidogrel and aspirin appeared to improve poor functional outcome at 90 days compared to aspirin, and this was consistent with a reduction in rate of disabling stroke in the dual antiplatelet arm. The rate of disability or death at 90 days was high, and clopidogrel was associated with $1.3 \%$ absolute reduction of poor functional outcome, which is equivalent to a number needed to treat of 21 patients to prevent a functional disability. Stratified analysis by stroke showed that there was no difference between 2 treatment groups in functional outcome and quality of life between 2 subgroups of no stroke or stroke.

Our data showed that clopidogrel plus aspirin reduced the absolute proportion of poor functional outcome ( $\mathrm{mRS}$ of 2 6 ) by $1.3 \%$ when compared with those on aspirin alone. The proportion of patients in the dimensions of mobility and activities associated with quality of life was also lower in the clopidogrel-aspirin group. This might be achieved through an absolute risk reduction of 7 patients for subsequent stroke, especially for disabling stroke. Furthermore, of patients experiencing subsequent stroke, approximately three-quarters were disabled or died (mRS of 2-6), while 7 patients without strokes had this poor outcome. Thus, the majority of strokes in the short term after ischemic stroke are disabling and the combination of clopidogrel and aspirin might lower this risk. With regard to more aggressive inhibition of platelet aggression for improving stroke disability, the ongoing Triple Antiplatelets for Reducing Dependency After Ischaemic Stroke (TARDIS) trial will determine whether triple antiplatelet strategy will be superior to dual antiplatelet therapy for reducing functional disability and dependence in patients with high risk of stroke ${ }^{[15]}$.

According to Nonparametric analysis in the original mRS did not show statistical difference in the functional outcome between 2 study groups but $\mathrm{X}^{2}$ analysis in the categorical $\mathrm{mRS}$ did; the reason for the difference in results between the ordinal $\mathrm{mRS}$ and the categorical $\mathrm{mRS}$ might be the unbalanced distribution of patients in each value of mRS. With regard to mRS as an ordinal or a categorical variable, which one has more power or whether they have equivalent power would be dependent on the pattern of treatment effect 
of intervention ${ }^{[16]}$. However, it might not be easy to determine patterns of clinical improvement, because real trials will generally show less pure patterns of response. Thus, given the unbalanced distribution of patients in each value of $\mathrm{mRS}$ and characteristics of the target population in this trial, the dichotomized mRS for this study might be a more appropriate approach than the ordinal mRS.

\section{Conclusion}

Our study shows that among patients with ischemic stroke who can be treated within 24 hours after onset of symptoms, the combination of clopidogrel and aspirin appears to be superior to aspirin alone in improving poor functional outcome measured by mRS 90 days after the initial event, and this is consistent with a reduction in the rate of disabling stroke in the dual antiplatelet arm. Together with its overall impact on stroke risk, this reinforces the evidence supporting its use.

\section{Reference}

1. Aho K, Harmsen P, Hatano S, Marquardsen J, Smirnov VE, Strasser T, et al. Cerebrovascular disease in the community: results of a WHO collaborative study. Bull World Health Organ 1980;58:113-130

2. Powers WJ, Rabinstein AA, Ackerson T, Adeove OM, Bambakidis NC, Becker K, et al. Guidelines for the Early Management of Patients with Acute Ischemic Stroke: A Guideline for Healthcare Professionals From the American Heart Association/American Stroke Association. Stroke 2018;49:e46-e110.

3. Kazui M, Nishiya Y, Ishizuka T, Hagihara K, Farid $\mathrm{NA}$, Okazaki $\mathrm{O}$, et al. Identification of the human cytochrome $\mathrm{P} 450$ enzymes involved in the two oxidative steps in the bioactivation of clopidogrel to its pharmacologically active metabolite. Drug Metab. Dispos 2009;38:92-99.

4. Yi X, Wang Y, Lin J, Cheng W, Zhou Q, Wang C, et al. Interaction of CYP2C19, P2Y12, and GPIIIa Variants Associates With Efficacy of Clopidogrel and Adverse Events on Patients With Ischemic Stroke. Clin. Appl. Thromb. Hemost 2016;23:761-768.

5. Siller-Matula JM, Petre A, Delle-Karth G, Huber K, Ay C, Lordkipanidzé $\mathrm{M}$, et al. Impact of preoperative use of P2Y12 receptor inhibitors on clinical outcomes in cardiac and non-cardiac surgery: A systematic review and meta-analysis. Eur. Heart J. Acute Cardiovasc. Care 2017;6:753-770.

6. Hasan MS, Basri HB, Hin LP, Stanslas J. Genetic polymorphisms and drug interactions leading to clopidogrel resistance: Why the Asian population requires special attention. Int. J. Neurosci 2012;123:143-154.

7. $\mathrm{Su} \mathrm{JF}, \mathrm{Hu} \mathrm{XH}, \mathrm{Li}$ CY. Risk factors for clopidogrel resistance in patients with ischemic cerebral infarction and the correlation with ABCB1 gene rs1045642 polymorphism. Exp. Ther. Med 2014;9:267-271.

8. Pan Y, Chen W, Xu Y, Yi X, Han Y, Yang QW, et al. Genetic Polymorphisms and Clopidogrel Efficacy for Acute Ischemic Stroke or Transient Ischemic Attack: A Systematic Review and Meta-analysis. Circulation 2017;135:21-33.

9. Jover E, Rodriguez JM, Bernal A, Arroyo AB. Iniesta, J.; Guiu, I.S.; Martinez, High on-treatment platelet reactivity in patients with ischemic cerebrovascular disease: Assessment of prevalence and stability over time using four platelet function tests. Blood Coagul. Fibrinolysis 2014;25:604-611.

10. Mega JL, Simon T. Pharmacology of antithrombotic drugs: An assessment of oral antiplatelet and anticoagulant treatments. Lancet 2015;386:281-291.

11. Leunissen TC, Janssen PW, Berg JMT, Moll FL, Korporaal SJ, de Borst GJ, et al. The use of platelet reactivity testing in patients on antiplatelet therapy for prediction of bleeding events after cardiac surgery. Vasc. Pharmacol 2016;77:19-27.

12. Ostrowska M, Kubica J, Adamski P, Kubica A, Eyileten C, Postula M, et al. Stratified Approaches to Antiplatelet Therapies Based on Platelet Reactivity Testing. Front. Cardiovasc. Med 2019;6:176.

13. Fu H, Hu P, Ma C, Peng F, He Z. Association of clopidogrel high on-treatment reactivity with clinical outcomes and gene polymorphism in acute ischemic stroke patients. An observational study. Medicine 2020;99:e19472.

14. Qiu LN, Wang L, Li X, Han RF, Xia XS, Liu J, et al. Predictive Value of High Residual Platelet Reactivity by Flow Cytometry for Outcomes of Ischemic Stroke Patients on Clopidogrel Therapy. J. Stroke Cerebrovasc. Dis 2015;24:1145-1152.

15. Rao Z, Zheng H, Wang F, Wang A, Liu L, Dong K, et al. High On-Treatment Platelet Reactivity to Adenosine Diphosphate Predicts Ischemic Events of Minor Stroke and Transient Ischemic Attack. J. Stroke Cerebrovasc. Dis 2017;26:2074-2081.

16. Orme R, Judge HM, Storey RF. Monitoring Antiplatelet Therapy. Semin. Thromb. Hemost 2017;43:311-319. 